\title{
Uterine cervical aplasia and agenesis
}

INSERM

\section{Source}

INSERM. (1999). Orphanet: an online rare disease and orphan drug data base. Uterine cervical aplasia and agenesis. ORPHA:180145

A rare, non-syndromic, uterovag inal malformation characterized by variable degrees of cervical aplasia, ranging from complete agenesis to the presence of a cervix with a cervical canal that contains a blind end. Patients typically present primary amenorrhea, cyclical abdominal or pelvic pain, dyspareunia and/or reproductive problems. 